Vikram J. Jaisinghani, M.D.,

Samuel C. Levine, M.D., Eric Nussbaum, M.D.,

Stephen Haines, M.D., and Bruce Lindgren, M.S.

\title{
Hearing Preservation after Acoustic Neuroma Surgery
}

\begin{abstract}
Acoustic neuromas (AN) are benign tumors that arise from the vestibular nerve within the internal auditory canal, where hearing loss is the most common symptom. This retrospective study was done to determine the results of hearing preservation in patients operated for AN at the University of Minnesota, as well as the factors affecting them. One hundred-eighty patients with AN were operated between 1988 and 1998, of whom 91 (50.5\%) underwent hearing preservation surgery by either the middle fossa (MF) or the suboccipital (SO) approach. Preoperative and postoperative pure-tone averages $(1,2$, and $4 \mathrm{~K})$, speech discrimination scores (SDS), and acoustic reflex thresholds (ART) were noted and classified according to the Shelton's and the Gardner's classifications. The overall rate of hearing preservation was $23.1 \%$. The outcome of hearing results was better with the MF approach compared with the SO approach. Small tumor size and better preoperative hearing levels favored a better postoperative hearing result. The rate of hearing improvement over time was better for the MF patients. Patients for whom intraoperative auditory monitoring was performed seemed to have better hearing outcomes.
\end{abstract}

With the advent of microsurgery, techniques for a removal of acoustic neuroma (AN) have improved over the years. We are at a point where tumor extirpation is not the only goal, as preservation of normal cochlear function can be obtained and expected as well, especially in the case of small tumors. The advent of MRI has enabled the surgeon to detect small tumors in asymptomatic patients; thus, preservation of hearing becomes more critical, with as many as $20 \%$ of patients with AN presenting as candidates for hearing preservation. ${ }^{1}$ This article presents the hearing results in our series of patients with $\mathrm{AN}$, operated on for hearing preservation surgery by the middle fossa (MF) or the suboccipital (SO) approach, as well as the factors influencing the final outcome.

\section{MATERIALS AND METHODS}

One hundred-eighty patients were operated on for removal of AN between 1988 to 1998 at the Department of Otolaryngology, University of Minnesota. A retrospective chart review was performed for patients who underwent AN with attempts at hearing preservation. In our series, the MF approach was used for laterally based intracanalicular tumors, whereas the SO approach was used for medially based tumors that extended into the cerebellopontine angle. All patients with serviceable hearing as determined preoperatively by Shelton's classification, pure-tone average (PTA) $<50$, and speech discrimination score $(\mathrm{SDS})>50$, were considered as candidates for hearing preservation surgery. Our series also includes some patients with measurable hearing during the preoperative period, when the surgeons attempted to preserve hearing, depending on how critical it was to the patient (i.e., for the patient's career or other personal reasons). In some cases, the opposite ear had a hearing loss. We evaluated the pre- and postoperative hearing results by recording the PTA, SDS, and acoustic reflex threshold (ART). Preoperative hearing levels were documented from the audiogram closest to the date of

Skull Base Surgery, Volume 10, Number 3, 2000 Department of Otolaryngology (VJJ), Department of Otolaryngology (SCL), Department of Neurosurgery (EN, SH), School of Public Health (BL), University of Minnesota, Minneapolis Minnesota. Reprint requests: Dr. Samuel C. Levine, Department of Otolaryngology, University of Minnesota, Box 396, Mayo Memorial Bldg., 420 Delaware Street SE; Minneapolis, MN 55455. Copyright (C) 2000 by Thieme Medical Publishers, Inc., 333 Seventh Avenue, New York, NY 10001, USA. Tel.: +1(212) 584-4662. 1052-1453;p,2000,10,03,141,148,ftx,en;sbs00185x 
surgery, whereas postoperative levels were documented from the last audiogram during follow-up visits. The PTA was calculated by taking the mean of the air conduction thresholds at 1000,2000 , and $4000 \mathrm{~Hz}$, a more stringent calculation of PTA. The hearing results were classified by Shelton's (see Table 2) and Gardner's (see Table 3) classifications. Patients with good or serviceable hearing postoperatively were considered to have had a successful attempt at surgery for hearing preservation. We noted those patients who underwent intraoperative auditory monitoring. The facial nerve outcome in the patients was also recorded. Tumor size was graded according to the classification proposed by Tos and Thomsen ${ }^{2}$ : intracanalicular, small (1 to $10 \mathrm{~mm}$ extrameatal size), medium ( 11 to $25 \mathrm{~mm}$ ), large (26 to 40 $\mathrm{mm})$, and very large $(>40 \mathrm{~mm})$.

Ninety-one $(50.5 \%)$ of 180 patients operated for AN underwent hearing preservation surgery by the MF or the SO approach. Thirty-five of these 91 (38.5\%) patients underwent AN resection by the MF approach (pre- and postoperative hearing levels available for 33), and $56(61.5 \%)$ patients were operated by the SO approach (pre- and postoperative hearing levels available for 45 patients). Statistical comparison between groups was done using the analysis of variance (ANOVA) or Student's $t$-test for continuous measures and the nonparametric Wilcoxon two-sample exact test for ordered categorical hearing levels.

\section{RESULTS}

The mean $( \pm S D)$ preoperative hearing levels of patients in the MF group were as follows: PTA, $35 \pm 19$ $\mathrm{dB}$; SDS, $90 \pm 16 \%$; and ART, $90 \pm 7 \mathrm{~dB}$. For the SO approach, they were PTA, $38 \pm 23 \mathrm{~dB}$; SDS, $82 \pm 27 \%$; and ART, $96 \pm 8 \mathrm{~dB}$. The differences in PTA and SDS between the two approaches were not significant $(p>$ 0.05 ), whereas the differences between the ART were statistically significant $(p=0.04)$. The mean differences between the postoperative and preoperative PTA for the MF and SO approaches are depicted in Table 1. These values were significantly higher for the SO group compared with the MF group, indicating that hearing preservation was better in the latter group. The overall incidence of hearing preservation was 18 of $78(23.1 \%)$ patients. Postoperatively, in 14 of 33 (42.4\%) patients

Table 1. Mean Difference Between Postoperative and Preoperative Hearing Levels

\begin{tabular}{lccc}
\hline & \multicolumn{3}{c}{ Hearing Results } \\
\cline { 2 - 4 } Parameter & Middle Fossa & Suboccipital & $p$ \\
\hline PTA (dB) & $11 \pm 20$ & $27 \pm 24$ & 0.02 \\
SDS (\%) & $-3 \pm 12$ & $-39 \pm 45$ & 0.02 \\
ART (dB) & $8 \pm 6$ & $-13 \pm 4$ & 0.02 \\
\hline
\end{tabular}

PTA $=$ pure-tone average $; A R T=$ acoustic reflex threshold $;$ SDS $=$ speech discrimination score.
Table 2. Hearing Results (Shelton's Classification) by Surgical Approach

\begin{tabular}{|c|c|c|}
\hline $\begin{array}{l}\text { Shelton's } \\
\text { Classification } \\
\text { (Postoperative } \\
\text { Hearing Levels) }\end{array}$ & $\begin{array}{c}\text { Middle Fossa } \\
\text { Approach } \\
(n=33)\end{array}$ & $\begin{array}{c}\text { Suboccipital } \\
\text { Approach } \\
(n=45)\end{array}$ \\
\hline $\begin{array}{l}\text { Good } \\
\text { PTA <30, } \\
\text { SDS >70 }\end{array}$ & $8(24.2 \%)$ & 0 \\
\hline $\begin{array}{c}\text { Serviceable } \\
\text { PTA }<50 \\
\text { SDS }>\mathbf{5 0}\end{array}$ & $6(18.2 \%)$ & $4(8.9 \%)$ \\
\hline $\begin{array}{c}\text { Measurable } \\
\text { Any, Any }\end{array}$ & $11(33.3 \%)$ & $14(31.1 \%)$ \\
\hline $\begin{array}{l}\text { No hearing, no } \\
\text { response }\end{array}$ & $8(24.2 \%)$ & $27(60 \%)$ \\
\hline
\end{tabular}

operated by the MF approach, hearing was preserved (8 with good hearing, 6 with serviceable hearing), 11 (33.3\%) patients had measurable hearing, and 8 (24.2\%) had no hearing. If we considered patients with postoperative measurable hearing levels to be "hearing preserved," our success rate would rise to $75.8 \%$. In the SO group, 4 of $45(8.9 \%)$ had preserved hearing (all in the serviceable group); 14 (31.1\%) had measurable hearing, whereas $27(60 \%)$ had no hearing. If we considered patients with postoperative measurable hearing levels to be "hearing preserved," our success rate would rise to $40 \%$. Details according to the Shelton's and Gardner's classifications are listed in Tables 2 and 3.

Preoperative versus postoperative hearing levels for the MF and SO approach are shown in Tables 4 to 7 according to the two classifications. In these tables, the preoperative hearing results are depicted vertically on the left side. For example, in the first row and first column, "7" represents patients with good preoperative hearing levels who also had good hearing levels postoperatively. Similarly, in the first row and second column, " 2 " represents the number of patients with good preoperative hearing levels, but had serviceable hearing postoperatively. The mean tumor size of patients who had hearing preservation postoperatively is presented in Table 8 . The differences in the mean tumor size among the three groups of Shelton's classification for the SO

Table 3. Hearing Results (Gardner's Classification) by Surgical Approach

\begin{tabular}{|c|c|c|c|c|}
\hline \multicolumn{3}{|c|}{$\begin{array}{c}\text { Gardner's Classification } \\
\text { (Postoperative Hearing } \\
\text { Levels) }\end{array}$} & \multirow{2}{*}{$\begin{array}{l}\text { Middle Fossa } \\
\text { Approach } \\
(n=33)\end{array}$} & \multirow{2}{*}{$\begin{array}{c}\text { Suboccipital } \\
\text { Approach } \\
(n=45) \\
\end{array}$} \\
\hline Grade & $P T A(d B)$ & $S D S(\%)$ & & \\
\hline 1 & 0-30 & 70-100 & $8(24.2 \%)$ & 0 \\
\hline 2 & $31-50$ & $50-69$ & $7(21.2 \%)$ & $5(11.1 \%)$ \\
\hline 3 & 51-90 & $5-49$ & $7(21.2 \%)$ & $10(22.2 \%)$ \\
\hline & $>90$ & $1-4$ & $3(9.1 \%)$ & $3(6.7 \%)$ \\
\hline \multicolumn{3}{|c|}{ No hearing } & $8(24.2 \%)$ & $27(60 \%)$ \\
\hline
\end{tabular}


Table 4. Middle Fossa Approach: Pre- Versus Postoperative Hearing Results by Shelton's Classification

\begin{tabular}{|c|c|c|c|c|c|}
\hline \multirow[b]{2}{*}{ Shelton's Classification } & \multicolumn{5}{|c|}{ Postoperative Hearing Levels } \\
\hline & Good & Serviceable & Measurable & No Hearing & Total \\
\hline $\begin{array}{l}\text { Gooda } \\
\text { Serviceablea } \\
\text { Measurable }^{\mathbf{a}}\end{array}$ & $\begin{array}{l}7(63.6 \%) \\
0 \\
1(12.5 \%)\end{array}$ & $\begin{array}{l}2(18.2 \%) \\
4(30.8 \%) \\
\underline{0}\end{array}$ & $\begin{array}{l}1(9.1 \%) \\
5(38.5 \%) \\
5(62.5 \%)\end{array}$ & $\begin{array}{l}1(9.1 \%) \\
4(30.8 \%) \\
2(25 \%)\end{array}$ & $\begin{array}{r}11 \\
13 \\
8 \\
\end{array}$ \\
\hline Total & $\overline{8}(25 \%)$ & $\overline{6}(18.8 \%)$ & $\overline{11}(34.4 \%)$ & $\overline{7 b}(21.9 \%)$ & $32^{b}$ \\
\hline
\end{tabular}

apreoperative hearing levels.

bPreoperative hearing levels of one patient not available.

approach were significantly different $(p=0.01)$. Hearing results according to tumor size groups are listed in Tables 9 and 10. Better hearing levels were observed in smaller tumors. We compared hearing results achieved with the two approaches within each tumor size group. Patients operated on by the MF approach still had better hearing levels than were found among those operated on by the SO approach. However, owing to the small sample size, we could only demonstrate a trend, but no statistical significance.

The rate of improvement (difference between last postoperative and first postoperative hearing levels, divided by follow-up time in months) in hearing levels over time postoperatively is listed in Table 11. The rate of improvement (especially the PTA) was better in the MF group. Hearing results with regard to intraoperative auditory monitoring are listed in Table 12. Comparison of the hearing results between the monitored and unmonitored groups indicated no statistically significant difference for the MF patients, which could be attributed to the very small sample size. However, in the SO group, the monitored patients had better hearing results than were found for the unmonitored group $(p=0.003)$. Overall, when we combined the two approaches, the monitored patients had better hearing outcomes than did the unmonitored patients $(p=0.002)$.

Immediate postoperative facial paresis/palsy occurred in $38.9 \%$ of our patients, MF, SO, and translabyrinthine (TL) patients combined, with the highest incidence in the SO approach and equal incidence in the MF and TL patients. Details of the facial nerve outcome in our series will be published in another article. Longterm follow-up evaluation showed that the facial nerve outcome was better with the MF group compared to the SO and the TL group. Cerebrospinal fluid (CSF) leaks occurred in $20.1 \%$ of patients, with the highest $(25.7 \%)$ in the MF group and the lowest (17.6\%) in the TL group.

\section{DISCUSSION}

The first cases of hearing preservation after surgical removal of AN were reported by Elliot and McKissock $^{3}$ in 1954. During the 1960 s, House ${ }^{4}$ developed the MF approach to the internal auditory canal (IAC) and was able to preserve hearing in a few intracanalicular tumors. It was not until the mid- to late 1970s that the literature reflected a new interest in hearing preservation predominantly by neurosurgeons employing the SO route. 5,6 Whether preservation of hearing is a reasonable objective has remained controversial. Past studies have shown that many patients find unilateral deafness a disability. ${ }^{7}$ In the North American survey of AN patients, $19 \%$ of patients reported the most difficult aspect of their recovery was the loss of hearing. ${ }^{8}$ These data suggest that hearing loss in a typical middle-aged schwannoma patient can lead to significant physical and psychosocial dysfunction. ${ }^{8}$ Hearing preservation in AN surgery is a very complex issue with many facets. Even after excluding patients with medium or large tumors, most surgical series report that only one-third of these preselected patients have preserved hearing after surgery. ${ }^{9}$

The literature is flooded with different classifications proposed by different surgeons. One is struck by the disarray of data, which has encumbered comparison

Table 5. Suboccipital Approach: Pre- Versus Postoperative Hearing Results by Shelton's Classification ${ }^{a}$

\begin{tabular}{|c|c|c|c|c|c|}
\hline \multirow[b]{2}{*}{ Shelton's Classification } & \multicolumn{5}{|c|}{ Postoperative Hearing Levels } \\
\hline & Good & Serviceable & Measurable & No Hearing & Total \\
\hline $\begin{array}{l}\text { Gooda } \\
\text { Serviceablea } \\
\text { Measurable }^{a}\end{array}$ & $\begin{array}{l}0 \\
0 \\
0\end{array}$ & $\begin{array}{l}1(7.14 \%) \\
2(14.3 \%) \\
1(8.3 \%\end{array}$ & $\begin{array}{l}4(28.6 \%) \\
5(35.7 \%) \\
5(41.7 \%)\end{array}$ & $\begin{array}{l}9(64.3 \%) \\
7(50 \%) \\
6(50 \%)\end{array}$ & $\begin{array}{l}14 \\
14 \\
12 \\
\end{array}$ \\
\hline Total & $\overline{0}$ & $\overline{4}(10 \%)$ & $\overline{14}(35 \%)$ & $\overline{22}(55 \%)$ & $\overline{40^{b}}$ \\
\hline
\end{tabular}

aFor preoperative hearing levels.

bPreoperative hearing levels of five patient not available. 
Table 6. Middle Fossa Approach: Pre- Versus Postoperative Hearing Results by Gardner's Classification

\begin{tabular}{|c|c|c|c|c|c|c|}
\hline \multirow[b]{2}{*}{ Gardner's Classification } & \multicolumn{6}{|c|}{ Postoperative Hearing Levels } \\
\hline & 1 & 2 & 3 & 4 & 5 & Total \\
\hline $1 \mathrm{a}$ & $7(63.6 \%)$ & $2(18.2 \%)$ & $1(9.1 \%)$ & 0 & $1(9.1 \%)$ & 11 \\
\hline $2^{a}$ & $1(6.7 \%)$ & $5(33.3 \%)$ & $3(20 \%)$ & $1(6.7 \%)$ & $5(33.3 \%)$ & 15 \\
\hline $3^{\mathbf{a}}$ & $\underline{0}$ & $\underline{0}$ & $\underline{3}(50 \%)$ & $\underline{2}(33 \%)$ & $\underline{1}(16.7 \%)$ & $\underline{6}$ \\
\hline Total & $8(25 \%)$ & $7(21.9 \%)$ & $7(21.9 \%)$ & $3(9.4 \%)$ & $7(21.9 \%)$ & 32 \\
\hline
\end{tabular}

aFor preoperative hearing results, read across. For postoperative hearing results, read down.

of hearing results between different series. Most series are small without adequate pre and postoperative audiometric studies to substantiate claims of hearing preservation. There is no agreement as to what constitutes serviceable or useful hearing. We share the wish expressed by several investigators that the presentation of results should be clarified and standardized.5,9 A consensus needs to be reached about the selection criteria for patients to undergo hearing preservation, grading, and classification of postoperative hearing results, as well as what defines preserved hearing. Glasscock et al. ${ }^{10}$ have discussed in the principles of binaural hearing in an effort to establish a definition of serviceable hearing. They note that the operated side in patients with unilateral tumor and a normal contralateral ear must maintain hearing at a level that can be substantially improved with a conventional hearing aid. They define an aidable ear as one that has a PTA of at least $70 \mathrm{~dB}$ and a SDS of $70 \%$ with normal dynamic range. ${ }^{10}$ The American Academy of Otolaryngology has endorsed the Shelton's classification, and this is a helpful step. Also, we think that the hearing result should not only consider the postoperative hearing levels in the operated ear but should also take into account the hearing levels of the contralateral or unoperated ear. Patients who have measurable hearing in the operated ear postoperatively, which can be improved with a hearing aid and with contralateral good hearing, may constitute cases of "preserved hearing." This will not only provide a true judgment about the patient's hearing status but will also assist surgeons in communicating realistic expectations to their patients regarding success in undergoing surgery for hearing preservation. The bottom line is that preserved hearing that can be aided is beneficial to the patient. In the process of decision making, one must take into consideration the patient's feelings and perception of whether the hearing in the affected ear is useful to them. If a patient feels strongly that he or she would like to attempt hearing preservation, those wishes should be honored. We have found that patients with better preoperative hearing levels had better postoperative hearing results. This observation has been reported by other studies as well. 17,20 Therefore, preoperative hearing levels appear to be an important factor influencing the outcome of hearing preservation.

Since 1985 , overall results have improved steadily and hearing preservation in unilateral AN has increasingly been documented. $9,11,12$ Overall hearing preservation rates reported in literature vary from $33 \%$ to $38 \% .9,10,13$ Our rates are on the lower side because we did not adhere to the commonly followed rule of 50/50 for preoperative PTA/SDS scores for selecting patients for hearing preservation. This rule is followed by most surgeons at various centers. We attempted to preserve hearing in patients with larger tumors, that is, cases that would otherwise have been rejected if the selection criteria had focused only on small tumors. The flexible criteria used for patient selection could attribute to the higher percentage of patients in our series undergoing hearing preservation surgery compared with other series, as well as the lower overall incidence of hearing preservation in our series. Had we adhered to rigid criteria, our rates for hearing conservation might have been higher.

Table 7. Suboccipital Approach: Pre- versus Postoperative Hearing Results by Gardner's Classification

\begin{tabular}{|c|c|c|c|c|c|c|}
\hline \multirow[b]{2}{*}{ Gardner's Classification } & \multicolumn{6}{|c|}{ Postoperative Hearing Levelsa } \\
\hline & 1 & 2 & 3 & 4 & 5 & Total \\
\hline 1 & 0 & $1(6.7 \%)$ & $3(20 \%)$ & $1(6.7 \%)$ & $5(66.7 \%)$ & 15 \\
\hline 2 & 0 & $3(20 \%)$ & $5(33.3 \%)$ & $1(6.7 \%)$ & $6(40 \%)$ & 15 \\
\hline \multirow[t]{2}{*}{3} & 0 & $1(12.5 \%)$ & $2(25 \%)$ & $1(12.5 \%)$ & $4(50 \%)$ & 8 \\
\hline & $\underline{0}$ & $\underline{0}$ & $\underline{0}$ & $\underline{0}$ & $2(100 \%)$ & $\underline{2}$ \\
\hline Total & $\overline{\mathbf{0}}$ & $5(25 \%)$ & $\overline{10}(12.5 \%)$ & $3(7.5 \%)$ & $22(55 \%)$ & 40 \\
\hline
\end{tabular}


Table 8. Hearing Results by Mean Tumor Size

\begin{tabular}{|c|c|c|c|c|}
\hline \multirow[b]{2}{*}{$\begin{array}{l}\text { Shelton's } \\
\text { Classification }\end{array}$} & \multicolumn{4}{|c|}{ Mean Tumor Size $( \pm S D)(\mathrm{mm})$} \\
\hline & $n$ & $\begin{array}{l}\text { Middle Fossa } \\
\quad(p>0.05)\end{array}$ & $n$ & $\begin{array}{c}\text { Suboccipital } \\
(p=0.01)\end{array}$ \\
\hline Go & 8 & 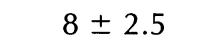 & 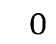 & $v$ \\
\hline & 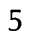 & $9 \pm$ & 4 & $9.5 \pm$ \\
\hline & 7 & $8.83 \pm 4$. & 11 & $15.5 \pm 8.5$ \\
\hline hearing & 6 & $9.3 \pm 4.17$ & 26 & $22.61 \pm 10.4$ \\
\hline
\end{tabular}

Hearing preservation using the MF approach has been reported to vary from $16 \%$ to $59 \%$, which is usually higher than by the SO approach. ${ }^{14-19}$ The SO approach is more commonly employed than the MF procedure for hearing preservation, especially by the neurosurgeons. Transient facial paralysis has been more commonly associated with the MF than with the SO approach. ${ }^{10}$ In our experience, transient facial nerve paralysis was almost the same for both the MF and the TL approaches. Our series demonstrated that the MF approach was associated with a higher rate of CSF leak. This could be attributed to the use of transtympanic electrocochleography for auditory nerve monitoring, which caused an iatrogenic perforation in the tympanic membrane. In our series, the MF group had a higher success rate of preservation compared with the SO approach; this could be attributed to the selection criteria for the SO surgical approach, which included some patients with larger tumors who had measurable, rather than serviceable, hearing preoperatively. This was done either because the tumor was in the only functioning ear or because it was critical to the patients occupation. The neurotologist and the neurosurgeon used their judgment in these cases after considering other associated factors (e.g., access to the tumor, difficulty in dissection of tumor, risk of facial palsy postoperatively) and to decide whether a particular patient warranted a surgical attempt at hearing preservation. It also allows for the possibility of improving the measurable hearing to a serviceable hearing in the future, using hearing aids or cochlear implants.

It has been reported that the potential for hearing preservation is inversely related to the size of the tumor. ${ }^{17.20}$ Some investigators have reported that their preservation success has diminished with a tumor size of
Table 9. Middle Fossa-Hearing Results by Tumor Size Group

\begin{tabular}{lcrc}
\hline \multirow{2}{*}{$\begin{array}{l}\text { Shelton's } \\
\text { Classification }\end{array}$} & \multicolumn{3}{c}{ Tumor Size Groups } \\
\cline { 2 - 4 } & Intracanicular & $1-10 \mathrm{~mm}$ & $11-25 \mathrm{~mm}$ \\
\hline Good & 0 & $7(37 \%)$ & $1(17 \%)$ \\
Serviceable & $1(14 \%)$ & $4(21 \%)$ & $1(17 \%)$ \\
Measurable & $4(57 \%)$ & $4(21 \%)$ & $2(33 \%)$ \\
No hearing & $\underline{2}(29 \%)$ & $\frac{4}{19}(21 \%)$ & $\frac{2}{6}(33 \%)$ \\
$\quad$ Total & 7 & 19 & 6 \\
\hline
\end{tabular}

$>1.5 \mathrm{~cm}^{16,18}$ or $>2.5 \mathrm{~cm} \cdot{ }^{19,21}$ This finding agrees with our observation that more patients in the MF group with an intracanalicular tumor or with a tumor of 1 to $25 \mathrm{~mm}$ have better results compared with those with larger tumor size. Hearing preservation in the SO group was lower in similar tumor size groups. Although hearing preservation was not achieved in a high percentage of patients with larger tumors, a reasonable number of patients had measurable hearing ( $33.3 \%$ with tumor size 11 to $25 \mathrm{~mm}$ in the MF and SO group; $12.5 \%$ with $26-$ to $40-\mathrm{mm}$ tumor size in the SO group). According to some investigators, attempts to preserve hearing should only be done in patients with AN $<20 \mathrm{~mm} .{ }^{19,20}$ Studies have demonstrated that the chance for successful hearing preservation is better with smaller tumors but, even with larger tumors (1 to $2 \mathrm{~cm}$ ), the success rate is reasonable. ${ }^{17}$ Successful hearing preservation in patients with $30-\mathrm{mm}$ AN has been achieved at some centers. ${ }^{22}$ In patients who have a strong desire to attempt hearing preservation, we agree with Jannetta et al..$^{5}$ and with Samii et al..$^{23}$ that surgeons should try to save hearing in any patient who has some degree of measurable hearing before surgery despite tumor size. However, these patients are made aware of the diminished chances of hearing preservation in tumors $>1.5 \mathrm{~cm}$. Thus, tumor size should not exclude the patient from an approach designed to preserve hearing.

Early diagnosis appears to be the key to a favorable outcome. In order to identify small tumors, even patients with minimal symptoms should be thoroughly evaluated, keeping the diagnosis of acoustic neuroma in mind. This requires a judicious, yet aggressive, use of audiometry (PTA, SDS, ART) and MRI.

There is no substitute for knowledge during surgery, but aids such as auditory monitoring can be beneficial.

Table 10. Suboccipital_-Hearing Results by Tumor Size Group

\begin{tabular}{|c|c|c|c|c|c|}
\hline $\begin{array}{l}\text { Shelton's } \\
\text { Classification }\end{array}$ & Intracanicular & $1-10 \mathrm{~mm}$ & $11-25 \mathrm{~mm}$ & $26-40 \mathrm{~mm}$ & $>40 \mathrm{~mm}$ \\
\hline Good & 0 & 0 & 0 & 0 & 0 \\
\hline Serviceable & 0 & $3(30 \%)$ & $1(5 \%)$ & 0 & 0 \\
\hline Measurable & 2 & $3(30 \%)$ & $7(33 \%)$ & $1(12 \%)$ & 0 \\
\hline No hearing & 1 & $4(40 \%)$ & $\underline{13}(62 \%)$ & $\underline{7}(88 \%)$ & $\underline{2}(100 \%)$ \\
\hline Total & 3 & 10 & 21 & 8 & 2 \\
\hline
\end{tabular}


Table 11. Rate of Improvement in Hearing Levels over Time during the Postoperative Period

\begin{tabular}{|c|c|c|}
\hline Hearing Results & $\begin{array}{c}\text { Middle Fossa } \\
(\text { Mean } \pm S D)\end{array}$ & $\begin{array}{l}\text { Suboccipital } \\
\text { (Mean } \pm S D)\end{array}$ \\
\hline PTA & $\begin{array}{c}-0.9 \pm 2.55 \mathrm{~dB} \\
(\mathrm{n}=21)\end{array}$ & $\begin{array}{c}-0.3 \pm 1.15 \mathrm{~dB} \\
(\mathrm{n}=10)\end{array}$ \\
\hline SDS & $\begin{array}{c}0.03 \pm 1.3 \% \\
(n=19)\end{array}$ & $\begin{array}{c}1.2 \pm 2.5 \% \\
(n=6)\end{array}$ \\
\hline
\end{tabular}

PTA $=$ pure-tone average; $\mathrm{SDS}=$ speech discrimination score

Competent and quick interpretation by the audiologist and appropriate communication between the audiologist and the surgeon are key first steps. Several techniques for intraoperative auditory monitoring have been described: brain stem auditory-evoked potentials (BAEP), electrocochleography (EcoG), or direct eighth nerve stimulation (VII-CAP). Each system has its drawbacks, principally the time delay inherent in averaging evoked responses and the technical difficulties of electrode positioning as well as stability in direct eighth nerve monitoring. The value of direct nerve monitoring for larger tumors, or for cases in which the cochlear nerve is not always easily identifiable, remains to be established. There is no overall agreement yet about the value of such methods in ensuring hearing preservation. ${ }^{18.25-30}$

Transtympanic EcoG has been used for most of our patients for intraoperative auditory monitoring. The advantages are that (1) recording electrode is not in the immediate surgical field obstructing the view or hampering the mobility of instruments; and (2) recording can be obtained before commencing the surgical commencing the surgical procedure, to establish a baseline recording. The disadvantages are (1) iatrogenic tympanic membrane perforation with an increased risk of postoperative CSF leak, and (2) the common problem of displacement of recording electrode.

It is difficult to comment on the value of intraoperative auditory monitoring. In our series, monitoring was performed in patients who had preoperative good or serviceable hearing levels, along with a recordable

Table 12. Hearing Results by Intraoperative Auditory Monitoring for Surgical Approaches

\begin{tabular}{|c|c|c|c|c|}
\hline \multirow{3}{*}{$\begin{array}{l}\text { Shelton's } \\
\text { Classification }\end{array}$} & \multicolumn{4}{|c|}{ Auditory Monitoring } \\
\hline & \multicolumn{2}{|c|}{$M F$} & \multicolumn{2}{|c|}{$S O$} \\
\hline & - & + & - & + \\
\hline Good & 0 & 8 & 0 & 0 \\
\hline Serviceable & 1 & 5 & 0 & 4 \\
\hline Measurable & 2 & 9 & 1 & 13 \\
\hline No hearing & $\underline{1}$ & 7 & $\underline{12}$ & $\underline{13}$ \\
\hline Total & $4(12.2 \%)$ & $29(87.9 \%)$ & $13(30.2 \%)$ & $30(69.7 \%)$ \\
\hline
\end{tabular}

ABR. This could be the reason for better overall outcome in patients who were monitored. Patients with recordable hearing levels preoperatively, but with no ABR response, were not monitored intraoperatively. This could be the cause of poor outcome in the unmonitored patients. Also, in these patients, the cochlear nerve was preserved and hearing loss probably occurred as a result of ischemia affecting the cochlea or cochlear nerves. This possibility is supported by Rowed and Nedzelski, ${ }^{24}$ who found that the continuous intraoperative monitoring of cochlear nerve action potentials (CNAP), with or without BAEPs did not prevent loss of serviceable hearing in one-half of patients with intracanalicular tumors. This does not mean that we do not recommend intraoperative cochlear monitoring. We would like to stress that it is not a foolproof method that guarantees hearing preservation; this approach does have some limitations. The decision as to which method is most appropriate depends on the surgeon's comfort level, personal experience, and available resources.

\section{CONCLUSIONS}

1. Hearing preservation in AN surgery is an achievable and reasonable objective.

2. Better results are obtained with the MF approach, in patients with smaller tumors, and in those with good preoperative hearing levels. Therefore, early diagnosis of small tumors becomes critical.

3. Results may not be very impressive by the suboccipital approach, with larger tumors, and in patients with poor postoperative hearing levels.

4. Patients with larger tumors with some preoperative hearing should not be denied the opportunity for an attempt at hearing preservation. Although the chances of obtaining a good hearing result are not very high in these patients, a postoperative "measurable" hearing level could be improved to "serviceable" hearing in the future by a hearing aid or cochlear implant.

5. The status of the contralateral ear needs to be considered while evaluating the hearing outcome after AN surgery. In addition, clear guidelines need to be defined to describe hearing preservation.

6. The rate of improvement in hearing levels over time, postoperatively, is better with the MF approach.

7. Intraoperative auditory nerve monitoring should be used as an adjunct to surgical skills in identifying the cochlear nerve for hearing preservation.

\section{REFERENCES}

1. Dornhoffer JL, Helms J. Hoehmann DH. Hearing preservation in acoustic tumor surgery: Results and prognostic factors. Laryngoscope 1995; 105:185-187

2. Tos M, Thomsen J. Proposal of classification in Acoustic 
Neuroma surgery. In: Tos M, Thomsen J, eds. Acoustic Neuroma. Proceedings of the First International Conference on Acoustic Neuroma, Copenhagen, Denmark, August 1991. Amsterdam Kugler, 1992:133-137

3. Elliot FA, McKissock W. Acoustic neuroma: Early diagnosis. Lancet 1954;2:1189-1191

4. House WF. Surgical exposure of the internal auditory canal and its contents through the middle cranial fossa. Laryngoscope 1961;71:1363-1385

5. Jannetta PJ, Møller AR, Møller MB. Technique of hearing preservation in small acoustic neuromas. Ann Surg 1984; 200:513-523

6. Ojemann RG, Levine RA, Montgomery WM, et al. Use of intraoperative auditory evoked potentials to preserve hearing in unilateral acoustic neuroma removal. J Neurosurg 1984;61:938-948

7. Bess FH, Lichtenstein MJ, Logan SA, Burger MC, Nelson E. Hearing impairment as a determinant of function in the elderly. J Am Geriatr Soc 1989;37:123-128

8. Weigand DA, Fickel V. Acoustic neuroma-the patients perspective: Subjective assessment of symptoms, diagnosis, therapy, and outcome in 541 patients. Laryngoscope 1989;99:179-187

9. Gardner G, Robertson JH. Hearing preservation in unilateral acoustic neuroma surgery. Ann Otol Rhinol Laryngol 1988; 97:55-66

10. Glasscock ME III, Hays JW, Minor ZB, Haynes DS, Carrasco VN. Preservation of hearing in surgery for acoustic neuromas. J Neurosurg 1993;78:864-870

11. Cohen NL, Hammersclag P, Berg H, et al. Acoustic neuroma surgery: an eclectic approach with emphasis on preservation of hearing-the New York-Bellevue experience. Ann Otol Rhinol Laryngol 1986;95:21-27

12. Frerebeau $P$, Benezech J, Uziel A, et al. Hearing preservation after acoustic neuroma operation. Neurosurgery 1987;21:197-200

13. Nedzelski JM, Chiong CM, Cashman MZ, Stanton SG, Rowed DW. Hearing preservation in acoustic neuroma surgery: value of monitoring cochlear nerve action potentials. Otolaryngol Head Neck Surg 1994;111:703-709

14. Hoehmann D. Pre and postoperative hearing thresholds and brainstem responses in patients with acoustic neuroma: Follow up study using the middle fossa approach. Am J Otol 1991;12:172-178

15. Shelton C, Brackmann DE, House HF, et al. Middle fossa acoustic tumor surgery: Results in 106 cases. Laryngoscope 1989;99:405-408

16. Gantz BJ, Parnes LS, Harker LA, et al. Middle cranial fossa acoustic neuroma excision: results and complications. Ann Otol Rhinol Laryngol 1986;95:454-459

17. Glasscock ME III, McKennan KX, Levine SC. Acoustic neuroma surgery: The results of hearing conservation surgery. Laryngoscope 1987;97:785-789
18. Silverstein $\mathrm{H}, \mathrm{McDaniel} \mathrm{AB}$, Norrell $\mathrm{H}$. Hearing preservation after acoustic neuroma surgery using intraoperative direct eighth cranial nerve monitoring. Am J Otol 1985;6(suppl):99-106

19. Harner SG, Laws ER Jr, Onofrio BM. Hearing preservation after removal of acoustic neurinomas. Laryngoscope 1984;94: 1431-1434

20. Shelton C, Brackmann DE, House WF, et al. Acoustic tumor surgery: Prognostic factors in hearing conservation. Arch Otolaryngol Head Neck Surg 1989;115;1212-1216

21. Nadol JB, Chiong CM, Ojemann RG, et al. Preservation of hearing and facial nerve function in resection of acoustic neuroma. Laryngoscope 1992;102:1153-1158

22. Fischer G, Costantini JL, Mercier P. Improvement of hearing after microsurgical removal of acoustic neurinoma. Neurosurgery 1980;7:154-159

23. Samii M, Turel KE, Penkert G. Management of seventh and eighth nerve involvement by cerebellopontine angle tumors. Clin Neurosurg 1985;32:242-272

24. Rowed DW, Nedzelski JM. Hearing preservation in the removal of intracanalicular acoustic neuromas via the retrosigmoid approach. J Neurosurg 1997;86:456-461

25. Nadol JB, Levine R, Martuza RJ, Ojemann RG, Montgomery $\mathrm{WW}$, et al. Preservation of hearing in surgical removal of acoustic neuromas in the internal auditory canal and cerebellar pontine angle. Laryngoscope 1987;97:1287-1294

26. Fischer G, Fischer C, Remond J. Pre- and intraoperative indicators for hearing preservation in suboccipital surgery. In: Tos M, Thomsen J, eds. Acoustic Neuroma. Proceedings of the First International Conference on Acoustic Neuroma, Copenhagen, Denmark, August 1991. Amsterdam: Kugler, 1992: 531-535

27. Kveton JF, Book J. A comparison of auditory nerve monitoring techniques in acoustic tumor surgery. In: Tos M, Thomsen J, eds. Acoustic Neuroma. Proceedings of the First International Conference on Acoustic Neuroma, Copenhagen, Denmark, August 1991. Amsterdam: Kugler, 1992:537-542

28. Maniglia AJ, Fenstermaker RA, Ratcheson PA. Preservation of hearing in the surgical removal of cerebellopontine angle tumors. Otolaryngol Clin North Am 1989;22:211-232

29. Prass RL, Kinney SE, Luders H. Transtragal, transtympanic electrode placement for intraoperative electrocochleographic monitoring. Otolaryngol Head Neck Surg 1989;97: 343-350

30. Symon L, Sabin H, Bentivoglio P, et al. Intraoperative monitoring of the electrocochleogram and the preservation of hearing during acoustic neuroma excision. Acta Neurochir (Wein) 1988;42(suppl):27-30 